\title{
MIX PROPORTIONING OF SELF COMPACTING CONCRETE USING LIMESTONE POWDER
}

\author{
AVRaZ ZainaldeEn ${ }^{1}$ and GHanim Hussein QOJA \\ Dept. of Civil Engineering, College of Engineering, University of Duhok, Kurdistan Region-Iraq
}

(Accepted for Publication: December 8, 2020)

\begin{abstract}
Self-compacting concrete (SCC) is a kind of concrete mixtures that can be used for placing in congested reinforcement structures without external vibrations. SCC has improved qualities and enhances concrete durability, working conditions, and productivity. This paper proposes an experimental procedure for the mix proportioning of SCC, considering M30 and M60 Grade concrete strength. Using limestone powder as a filler based on the aggregate packing principle and EFNRAC guideline for mix design. The tests that represent the properties of SCC in the plastic stage such as; V-funnel, slump flow, T500, L-Box, J-ring, and Sieve Segregation resistance were carried out. While in the hardened stage, the compressive strength was obtained at the ages of 7, 14, 28, and 56 days. The test results show that using 88 $\mathrm{kg}$ of limestone powder per unit volume can produce successfully SCC with compressive strength of 74.3 MPa at 56 days while using $225 \mathrm{~kg}$ of limestone powder produce SCC of compressive strength of $36.7 \mathrm{MPa}$ at 56 days.
\end{abstract}

KEYWORDS: Self- compacting concrete; Limestone Powder; Flow Ability; Compressive Strength.

\section{INTRODUCTION}

$\mathbf{R}$ ecently, the world is subjected to an increase in population, which is the main reason for the high demand for reinforced concrete structure for new structural design ideas. Consequently, design of reinforced concrete structure becomes more complex also the steel reinforcement in the structure is denser and highly congested than before, therefore compacting and flow of concrete are the main problem during pouring concrete. Besides, placing and compacting of normal concrete may need more time and this may lead to a loss in concrete workability and durability problem issues of the structure.

Self-compacting concrete (SCC) offers a solution to overcome many problems that subjected to casting normal concrete due to its high ability to pass and fill in the form and good resistance to segregation (Kareem, 2016). With these valuable properties, the produced SCC can enhance the durability and reliability of the reinforced concrete structures to a large extent. Also, SCC provides a good performance in strength and can achieve other construction requirements such as increase productivity, construction elements with limited compaction possibilities and congested steel reinforcement, exposed concrete parts where high surface quality is required, texture surfaced concrete construction elements, and reinforced concrete parts in environmentally noise-sensitive sites (Nan Su, 2001)

In Japan and about 40 years ago, the main concern of concrete developers is on the durability issues of concrete structure and they found that lack of compaction is the main cause of durability losses. on the other side, a reduced number of skilled laborers and an increase in using steel reinforcement in the construction industry in Japan was an obstacle to produce full compaction in concrete. Under such circumstances, there was a poor quality of concrete structures of low durability_( (Hajime Okamura, 2003).

In 1986, Professor Okamura at the University of Tokyo came up with the idea of SCC to overcome drawbacks related to the use of normal concrete for the purpose of increasing filling ability properties of concrete when intended to be used in complicated formworks or in forms of congested steel reinforcement.

At the end of the 1990s, the SCC technology spread in Europe and started from Sweden and moves to other Scandinavian countries, especially in Denmark which about $20 \%$ of total concrete production in ready mixes are using the SCC technique, also about $30 \%$ of the pre-cast productions is made from SCC. However, in 
other countries such as Germany, UK, France, and the USA there was temporary stagnation in using SCC due to lower resistance to segregation of SCC in comparison with normal concrete. (Thrane L N, 2004).

Continuous development of SCC enhances both the conceptual approach and method of construction for reinforced concrete structures and provides new recommendations for design. Currently, SCC is used widely, especially for heavily reinforced structures, tunnel linings, and, where normal concrete is not able to fill out the formwork properly. Also, the precast industry gains a great advantage of using SCC.

There is various mix design methods have been proposed for SCC, which can be classified into five different categories based on their methodological approach (Caijun Shi, 2015): empirical design method, compressive strength method, aggregates packing method, based on paste rheology method, and statistical methods. In the empirical design method, the aggregate content keeps constant and self-compactibility performance is provided by adjusting the water to powder ratio and the superplasticizer dosage, while The methodology in aggregate packing method is to minimize the voids between aggregate through the filled paste. In compressive strength method is essential to adjust all parameters to finalize the mix design.
The paste rheology method is based on the assumption which the rheology of the paste (yield stress and viscosity) affects the flowability and segregation resistance of the mix. The statistical method is based on statistical techniques of the results obtained from testing different SCC mixes (Sadowski, 2018).

This paper describes a procedure specifically developed to achieve SCC base on the packing factor method using local materials from the Kurdistan region of Iraq. The SCC is produced using limestone powder (locally available material) as a filler. It improves both the workability and the hardened properties of concrete (Gritsada Sua-iam, 2013). Also, the test results for acceptance properties for selfcompacting concrete such as V-funnel, slump flow, J-ring, L-Box, and segregation resistance are presented. Further, the strength characteristics in terms of compressive strength for 7-days, 14 - days, 28-days, and 56-days are also presented.

\section{MATERIALS USED}

\subsection{Cement}

The Ordinary Portland cement from Delta cement factory in Sulaymaniyah city was used and its properties are shown in Table 2.1 below.

Table (2.1): Physical properties of cement

\begin{tabular}{ll}
\hline Physical Properties & Result \\
\hline Finesses & $313 \mathrm{~m}^{2} / \mathrm{kg}$ \\
\hline Initial Setting & $197.7 \mathrm{~min}$. \\
\hline Final Setting & $4.15 \mathrm{hours}$ \\
\hline Compressive Strength (3 Days) & $25.9 \mathrm{MPa}$ \\
\hline Compressive Strength (7 Days) & $35.2 \mathrm{MPa}$ \\
\hline Soundness & 1.0 \\
\hline Specific Gravity & $3.15 \mathrm{~g} / \mathrm{cm}^{3}$ \\
\hline
\end{tabular}

\subsection{Coarse Aggregate}

Locally crushed coarse aggregate from the Khazeer query- Duhok governorate with the nominal maximum aggregate size of $20 \mathrm{~mm}$ was used. The physical properties and gradation of coarse aggregate are shown in Table 2.2 and 2.3 respectively.

Table (2.2): Physical properties of coarse aggregate

\begin{tabular}{lcc}
\hline Properties & Result & Test Method \\
\hline Bulk Specific Gravity & 2.72 & ASTM C127 \\
\hline Apparent Specific Gravity & 2.76 & ASTM C127 \\
\hline Absorption \% & 0.54 & ASTM C127 \\
\hline Bulk Density* $\mathrm{kg} / \mathrm{m}^{3}$ & 1430 & ASTM C29 \\
\hline Voids \% & 47.4 & ASTM C29 \\
\hline
\end{tabular}

* Bulk Density at loosely packed state according to ASTM C29

avraz_d@hotmail.com; ghanim.qoja@uod.ac

${ }^{1}$ Corresponding author: College of Engineering, University of Duhok, Kurdistan Region, Iraq 
Table (2.3): Gradation of coarse aggregate

\begin{tabular}{lll}
\hline Sieve Size & Passing \% & ASTM C33 \\
\hline 1 in & 100 & 100 \\
\hline $3 / 4$ in & 99 & $90-100$ \\
\hline $1 / 2$ in & 57 & $\ldots$ \\
\hline $3 / 8$ in & 34 & $20-55$ \\
\hline$\# 4$ & 4 & $0-10$ \\
\hline$\# 8$ & 1 & $0-5$ \\
\hline
\end{tabular}

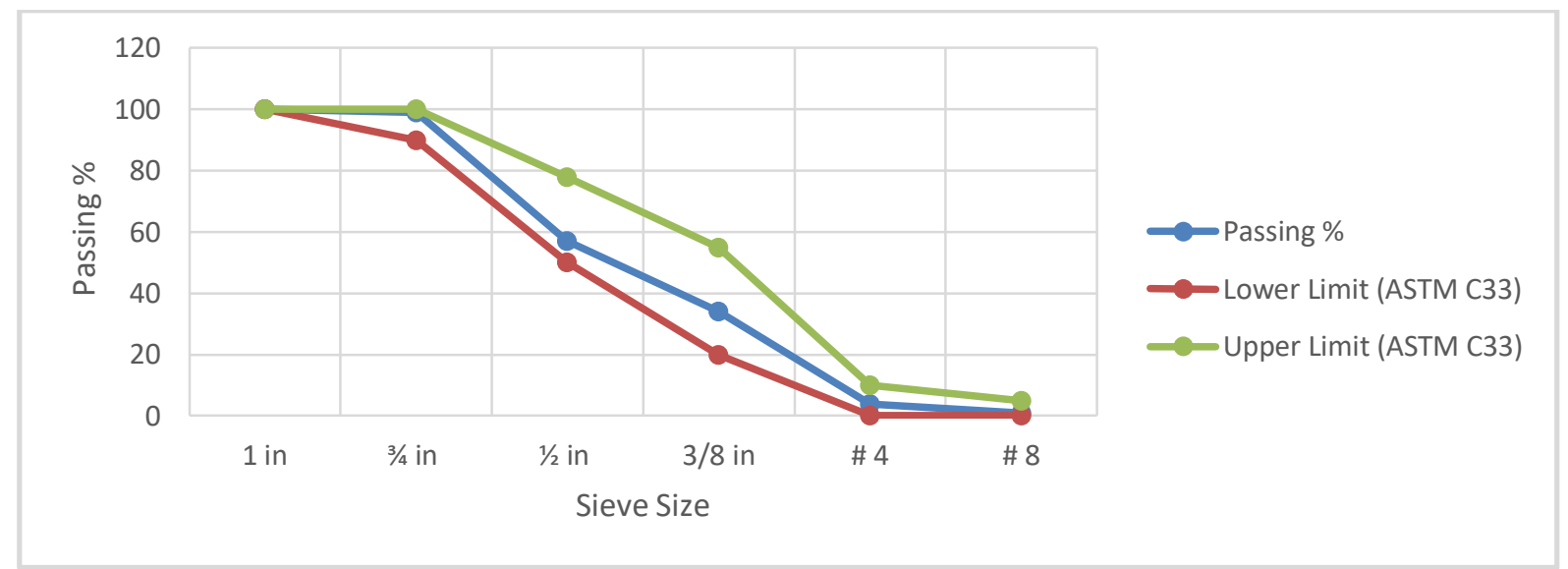

Fig. (2.1): Gradation of coarse aggregate

\subsection{Fine Aggregate}

Locally available natural sand with $4.75 \mathrm{~mm}$ maximum size taken from Khazeer query-
Duhok governorate was used as fine aggregate, having physical properties shown in Table 2.4 and grading given in Table 2.5.

Table (2.4): Physical properties of fine aggregate

\begin{tabular}{lcc}
\hline Properties & Result & Test Method \\
\hline Bulk Specific Gravity & 2.63 & ASTM C127 \\
\hline Apparent Specific Gravity & 2.75 & ASTM C127 \\
\hline Absorption \% & 1.7 & ASTM C127 \\
\hline Bulk Density* $\mathrm{kg} / \mathrm{m}^{3}$ & 1666 & ASTM C29 \\
\hline Voids \% & 36.5 & ASTM C29 \\
\hline Finesses Modules & 2.85 & ASTM C33 \\
\hline * Bulk Density at losely packed state according to ASTM C29 & &
\end{tabular}

* Bulk Density at loosely packed state according to ASTM C29

Table (2.5): Gradation of fine aggregate

\begin{tabular}{lll}
\hline Sieve Size & Passing \% & ASTM C33 \\
\hline $4.75 \mathrm{~mm}$ & 99.5 & $95-100$ \\
\hline $2.36 \mathrm{~mm}$ & 81 & $80-100$ \\
\hline $1.18 \mathrm{~mm}$ & 65 & $50-85$ \\
\hline $0.6 \mathrm{~mm}$ & 47.5 & $25-60$ \\
\hline $0.3 \mathrm{~mm}$ & 16.8 & $5-30$ \\
\hline $0.15 \mathrm{~mm}$ & 4.2 & $0-10$ \\
\hline
\end{tabular}

avraz_d@hotmail.com; ghanim.qoja@uod.ac 


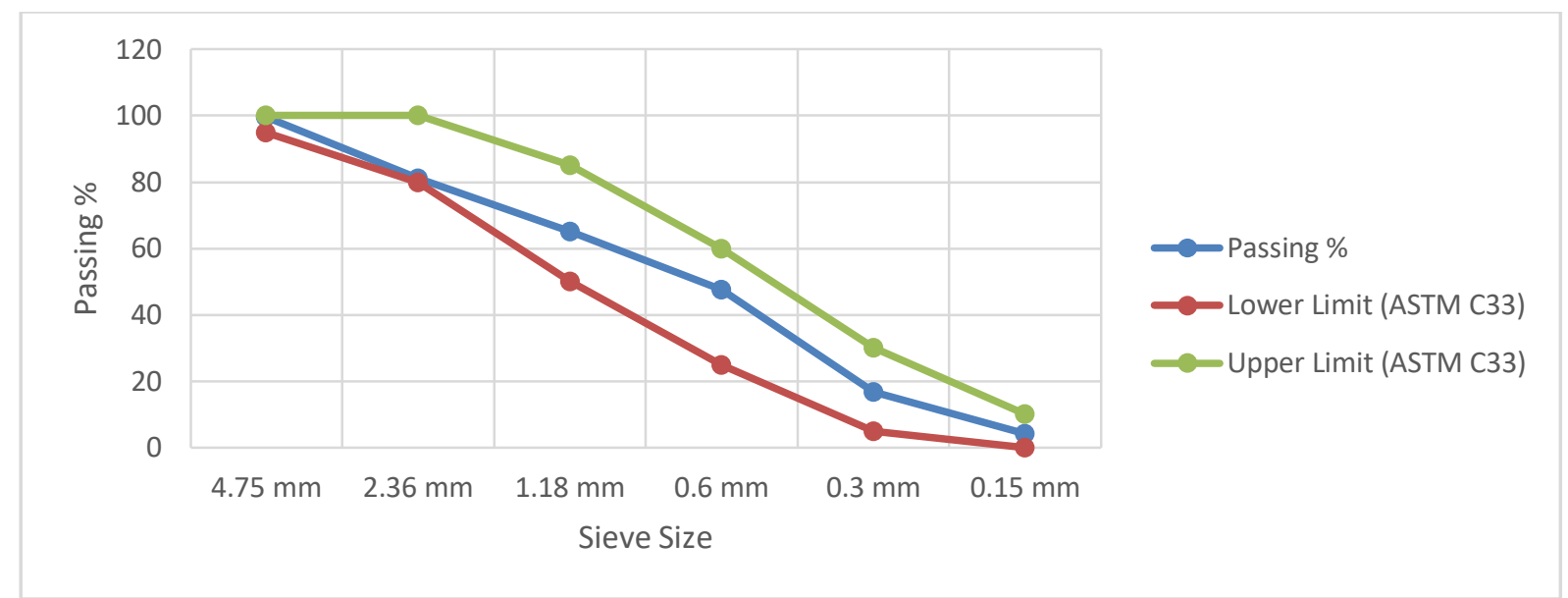

Fig. (2.2): Gradation of fine aggregate

\subsection{Limestone Powder:}

Finely crushed limestone which has been brought from Kuashi (industrial area in Duhok) with specific gravity 2.71 was used. This material was used as a filler as was found to pass on $75 \mu \mathrm{m}$ (No. 200) sieve.

\subsection{Superplasticizer}

A modified polycarboxylates based polymer known commercially as an (Sika-ViscoCrete hitech 1316) from Basra-Iraq was used as a high range water reducer agent (HRWRA). The HRWRA conformed the requirement of ASTM C494- Type F, G. Table 2.6 shows the technical data of the superplasticizer used throughout this study.

Table (2.6): Technical data of superplasticizer

\begin{tabular}{ll}
\hline Chemical Base & $\begin{array}{l}\text { Modified polycarboxylates based } \\
\text { polymer }\end{array}$ \\
\hline Density & $1.123 \mathrm{~kg} / \mathrm{l}$ \\
\hline pH Value & $6-8$ \\
\hline Freezing Point & $-5^{\circ} \mathrm{C}$ \\
\hline Solid Content & $40 \%$ by the weight \\
\hline Appearance & Brownish liquid \\
\hline
\end{tabular}

\section{Mix Design Procedure of the Proposed Method.}

The concept of the mix design of SCC using local material is based on the principle of combining Nan $\mathrm{Su}$ method and EFNARC guidelines for SCC. Nan Su method considers that paste of binder in loosely packed aggregate is responsible for providing workability properties of SCC in fresh state and strength by binding the aggregate through the paste in the hardened state. Consequently, the aggregate content, binder content, water content, and SP are the key factors affecting the properties of SCC. The below mix design procedure can be used to produce a SCC having good flowability, passing ability, and segregation resistance.

3.1 Step 1: Calculation of Aggregate

When water and binder are added to the loosely packed aggregate, the paste fills the voids between aggregate and lubrication occurs then the aggregates become more packed. Therefore, the aggregate content in SCC is controlled by packing factor (PF) which can be defined as the ratio of the mass of aggregate in the tightly packed state to mass of aggregate in the loosely packed state (Nan Su, 2001).

Increasing the PF will increase aggregate content in SCC consequently reduce the binder material then decrease the workability, therefore, it is very important to choose the optimal packing factor that makes a balance between workability properties and economic consideration of SCC.

The fine aggregate and coarse aggregate content can be evaluated using Equation (Eq. 1 and Eq.2) below:

avraz_d@hotmail.com; ghanim.qoja@uod.ac

${ }^{1}$ Corresponding author: College of Engineering, University of Duhok, Kurdistan Region, Iraq 


$$
\begin{array}{r}
W s=P F \times W s l \times\left(\frac{s}{a}\right) \\
W c=P F \times W c l \times\left(1-\frac{s}{a}\right)
\end{array}
$$

Where Ws: fine aggregate content in $\left(\mathrm{kg} / \mathrm{m}^{3}\right)$; Wsl: Loose density of fine aggregate $\left(\mathrm{kg} / \mathrm{m}^{3}\right)$ as per ASTM C29; PF: packing factor; Wc: coarse aggregate content; Wcl: Loose density of coarse aggregate $\left(\mathrm{kg} / \mathrm{m}^{3}\right)$ as per ASTM C29; s/a: the ratio of fine aggregate to total aggregate content, according to $\mathrm{Nan} \mathrm{Su}$, s/a ranges from $(50 \%$ to $57 \%$ ) while EFNRAC state that typical value of s/a is ranging from (48\% to 55\%). According to the trail mix that carried out in this study, an increase in sand content will overcome the bleeding problem and increase flowability, therefore, we recommend that the values of (s/a) should be range between (50\% to $57 \%$ ) as stated in Nan su.

\subsection{Step 2: Calculation of Cement Content}

Cement content can be calculated from Equation (Eq.3) below

$$
C=\frac{f c^{\prime}}{0.138}
$$

Where C: cement in $\mathrm{kg} / \mathrm{m}^{3}$, and $f_{c}^{\prime}$; designed cylinder compressive strength in $\mathrm{MPa}$.

\subsection{Step 3: Calculation of Mixing Water}

The required water/cement ratio (W/C) for SCC can be evaluated using ACI 318 or other recommendations from ACI code and then the water required for cement (Wwc) can be evaluated from equation Eq.4 below.

$W w c=\left(\frac{w}{c}\right) \times C$

\subsection{Step 4: Calculation of Limestone Powder}

filling ability, passing ability, and segregation resistance are the main behavior of SCC and it can be improved through combining powders and Portland cement. The main target of using the powder in SCC is to improve the particle packing and grain-size distribution, thus providing greater cohesiveness (ACI237R-07, 2007). There is much research that calculates the limestone powder as a function of replacement percent of cement but in this method, the exact value of limestone powder required for SCC can be driven from Equation (Eq.5) and (Eq.6) below.

$$
V p=1-\left(\frac{W c}{1000 \times S g . c a}+\frac{W s}{1000 \times S g . s}+\frac{C}{1000 \times S g . c}+\frac{W w c}{1000}+V a\right)
$$

Where Vp: volume of powder paste. Sg.ca: specific gravity of coarse aggregate, Sg.s; specific gravity of fine aggregate, Sg.c: specific gravity of cement, Wwc: water required for cement and Va: Volume of air content.

$$
\begin{aligned}
& V p=V w . l p+V . l p \\
& V p=\left(\frac{(W / C) \times W \cdot l p}{1000}\right)+\left(\frac{W . l p}{S g . l p \times 1000}\right)
\end{aligned}
$$


Where Vp: volume of powder paste (from equation (Eq.5)), W.Ip: the weight of limestone powder, Sg.pl: Specific gravity of Limestone powder and Vw.lp: volume of water required for limestone powder.

\subsection{Step 5: Calculation of Superplasticizer} (SP)

SP has a significant effect on SCC properties, which is increasing the ability of concrete to follow significantly. High dosage of SP will cause bleeding and decrease the strength of SCC (M. Benaicha, 2019) while the low dosage of SP will reduce follow ability of mix thus reduce the performance of SCC, therefore, the optimal dosage of SP should be chosen which is depend on w/c ratio, type of SP and type of filler. The weight of required SP and water content can be driven from equation (Eq.7) and (Eq.8).

$$
\begin{aligned}
& W s p=S P \%(W c+W . l p) \\
& W w s p=(1-S \%) W s p
\end{aligned}
$$

Where Wsp: the weight of superplasticizer in $\mathrm{kg} / \mathrm{m}^{3}, \mathbf{S P} \%$ : percent of superplasticizer, Wwsp: water content in SP and $\mathbf{S} \%$ : percent of solid content in SP.

3.6 Step 6: Calculate for Total Water Content

Total water (Wtw) required for SCC can be evaluated from equation (Eq.9) below:

$$
W t w=W w c+W w \cdot l p-W w s p
$$

\subsection{Step 7: Comparison of Material Content to EFNARC Guidelines.}

To minimize the trail mix, all material content should be fall in typical ranges provided by (EFNARC, 2005) guideline as shown in Table 4.2.

\subsection{Step 8: Trail Mixes}

After material content has been calculated from the above procedures, trail mixes should be carried out and tests performed to evaluate the fresh properties of SCC as shown in Table 5.1.

During trail mixes, the main variable will be PF. For instance, if the mix has high viscosity (low flowability and passing ability), PF should be decreased to increase the paste content of the mix, while if the mix has low viscosity (bleeding) PF. Should be increased.

\section{EXAMPLE OF CALCULATION OF THE PROPOSED METHOD}

For the local material that properties are shown in section 2.0, below is a sample calculation of SCC mix with cube compressive strength $\left(f_{c k}\right)$ of $60 \mathrm{MPa}$ for 28 days and air content of $2 \%$.

\subsection{Calculation for Target Compressive Strength (Fm)}

The target compressive strength $\left(f_{m}\right)$ can be evaluated from equation (Eq.10)

$$
f_{m}=f_{c k}+1.64 \times S
$$

Where $f_{c k}$ : is the designed compressive strength of cube and S: standard deviation

$f_{m}=60+1.64 \times 5=68.2$

$f_{c}{ }^{\prime}=68.2 \times 0.82=56 \mathrm{MPa}$

\subsection{Determine Aggregate Content:}

Assume PF equals 1.11 (after several trials on SCC to satisfy its fresh properties for compressive strength $60 \mathrm{MPa}$ the optimal $\mathrm{PF}$ is found to be 1.11 as shown in Table 6.1).

Assume Sand content is $52 \%$ from total aggregate content (section 3.1)

Fine aggregate content per $1 \mathrm{M}^{3}$ from Eq.1:

$\mathrm{Wg}=1.11 \times 1666 \times 52 \%=962 \mathrm{~kg} / \mathrm{m}^{3}$

Coarse aggregate content per $1 \mathrm{M}^{3}$ from Eq.2:

$\mathrm{Wc}=1.11 \times 1430 \times(1-52 \%)=762 \mathrm{~kg} / \mathrm{m}^{3}$

\subsection{Determine Cement Content}

From equation Eq. 3 and for $f_{c}{ }^{\prime}=56 \mathrm{MPa}$

$$
C=\frac{56}{0.138}=406 \mathrm{~kg} / \mathrm{m}^{3}
$$

\subsection{Determine Water Required for Cement}

From (ACI 211.4R-08) the recommended maximum water/cementitious ratio for compressive strength (56 MPa) is 0.35 , therefore the water content for cement is:

$\mathrm{Wwc}=406 \times 0.35=142.1 \mathrm{~kg} / \mathrm{m}^{3}$

\subsection{Determine limestone powder content:}

from Eq.5 the volume of powder paste is:

$$
V p=1-\left(\frac{762}{1000 \times 2.72}+\frac{962}{1000 \times 2.63}+\frac{406}{1000 \times 3.15}+\frac{142.1}{1000}+0.02\right)=0.063
$$


From Eq.6 the weight of limestone powder is: $0.063=\left(\frac{0.35 \times W . l p}{1000}\right)+\left(\frac{W . l p}{2.72 \times 1000}\right)$ $\mathrm{W} . \mathrm{lp}=88 \mathrm{~kg} / \mathrm{m}^{3}$

\subsection{Determine water required for limestone powder:}

For $\mathrm{w} / \mathrm{cm}=0.35$ the required water for limestone powder is:

Ww.lp $=88 \times 0.35=30.8 \mathrm{~kg} / \mathrm{m}^{3}$

\subsection{Determine SP content:}

According to the trail mix that carried out for this mix, the optimum dosage of SP (Sika viscocrete hi-tech 1316) is $0.6 \%$ and from Eq.7 the weight of SP is:

$\mathrm{Wsp}=0.6 \%(406+88)=2.96 \mathrm{~kg} / \mathrm{m}^{3}$

4.8 Determine Total Water Content
The solid content in SP is $40 \%$ and from Eq. 8 the water from SP is

Wwsp $=(1-40 \%) \times 2.96=1.77 \mathrm{~kg} / \mathrm{m}^{3}$

The total water content is:

$\mathrm{Wtw}=142.1+30.8-1.7=170 \mathrm{~kg} / \mathrm{m}^{3}$

\subsection{Comparison with EFNARC Guideline}

Table 4.2 shows the comparison of SCC mix content with typical constituent as per (EFNARC, 2005) guidelines.

4.10 Trail Mixes

A trail mix is made on different PF, the test result of the workability of SCC mixes are shown in table 6.1. The same procedure has been made for concrete with compressive strength $\left(f_{c k}\right.$ $=30 \mathrm{MPa}$ ), the final constituents in $\mathrm{kg}$ per unit volume of SCC with compressive strength 30 and $60 \mathrm{MPa}$ are shown in table 4.1 below.

Table (4.1): Constituents of SCC

\begin{tabular}{lll}
\hline Constituent & SCC (M60) & SCC (M30) \\
\hline Cement & 406 & 217 \\
\hline Sand & 962 & 979 \\
\hline Coarse Aggregate & 762 & 776 \\
\hline Water & 170 & 167 \\
\hline Limestone Powder & 88 & 225 \\
\hline SP & $2.96(0.6 \%)$ & $3.32(0.75 \%)$ \\
\hline $\mathrm{PF}^{*}$ & 1.11 & 1.13 \\
\hline${\mathrm{S} / \mathrm{A}^{* *}}$ & $52 \%$ & $52 \%$ \\
\hline
\end{tabular}

$\mathrm{PF}^{*}=$ Packing factor

$\mathrm{S} / \mathrm{A}^{* *}=$ percent of sand to total aggregate

Table (4.2): Comparison of constituents of SCC with EFNARC recommended range

\begin{tabular}{llll}
\hline Constituent & $\begin{array}{l}\text { EFNARC Recommended } \\
\text { Range }\end{array}$ & SCC(M60) & SCC(M30) \\
\hline $\begin{array}{l}\text { Water/Powder Ratio by } \\
\text { volume }\end{array}$ & $0.85-1.10$ & 1.053 & 1.09 \\
\hline Total Powder Content $\left(\mathrm{kg} / \mathrm{m}^{3}\right)$ & $380-600$ & 494 & 443 \\
\hline $\begin{array}{l}\text { Coarse Aggregate Content } \\
\left(\mathrm{kg} / \mathrm{m}^{3}\right)\end{array}$ & $750-1000$ & 761 & 775 \\
\hline $\begin{array}{l}\text { Coarse Aggregate Content by } \\
\text { volume }\end{array}$ & $\begin{array}{l}(28-35) \% \text { of the volume of } \\
\text { the total mix }\end{array}$ & $28 \%$ & $28.5 \%$ \\
\hline Sand Content & $(48-55) \%$ of total aggregate & $55 \%$ & $55 \%$ \\
\hline Paste Content $\left(\mathrm{lit} / \mathrm{m}^{3}\right)$ & $300-380$ & 354 & 343 \\
\hline Water Content $\left(\mathrm{kg} / \mathrm{m}^{3}\right)$ & $150-210$ & 167 & 170 \\
\hline
\end{tabular}

\section{TEST METHOD ON FRESH SCC}

In the fresh state the main properties of SCC are passing ability, filling ability, and segregation resistance, therefore a set of tests as shown below are used to evaluate the workability properties of SCC in a fresh state. Table 5.1 shows the recommended limit for different tests.

avraz_d@hotmail.com; ghanim.qoja@uod.ac 
Table (5.1): Typical range of different test

\begin{tabular}{lll}
\hline Property & Type of Test & Typical Range \\
\hline Filling ability & Slump Flow Test & $650-800 \mathrm{~mm}$ \\
\hline Filling ability & $\mathrm{T}_{500}$ & $2-5 \mathrm{Sec}$. \\
\hline Filling ability & V-Funnel & $8-12 \mathrm{Sec}$. \\
\hline Passing Ability & L-Box & $0.8-1$ \\
\hline Passing Ability & J-Ring & $\leq 10 \mathrm{~mm}$ \\
\hline Segregation Resistance & Sieve Segregation Resistance & $\leq 15 \%$ \\
\hline
\end{tabular}

The slump flow test is used to evaluate the flow of SCC horizontally without obstructions. The average diameter of the concrete circle is a measure for the slump flow, Figures $\mathbf{5 . 1}$ and $\mathbf{5 . 2}$ show the slump flow of concrete mix SCC(M60)

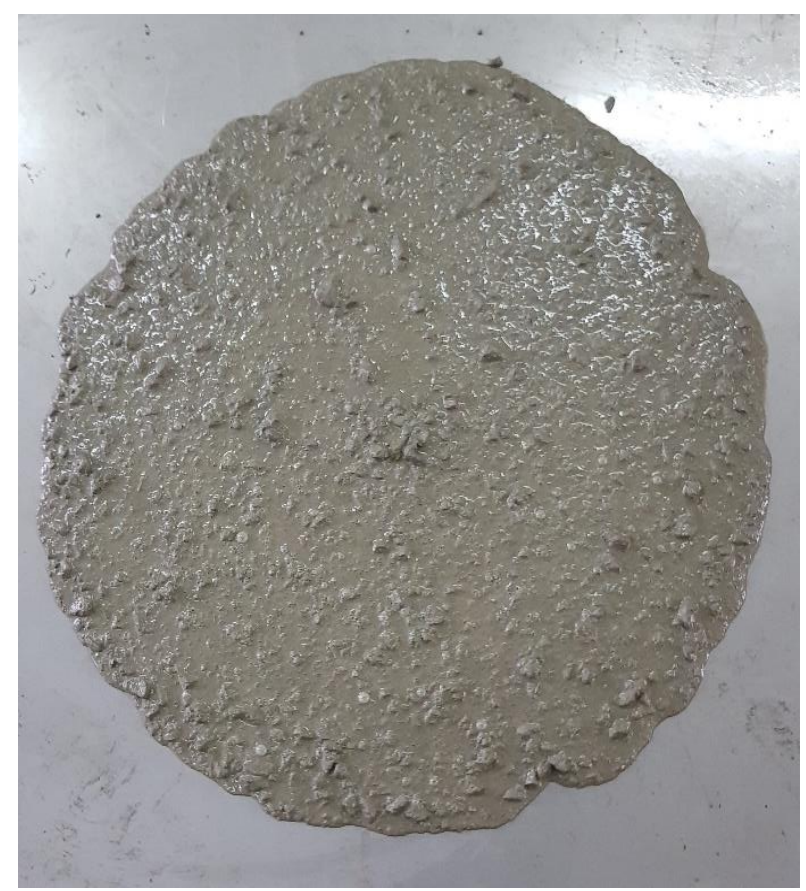

Fig. (5.1): Flow test of mix SCC(M60)

V-funnel test assessed the flowability of the fresh SCC, in which the funnel of $\mathrm{V}$ shape is filled with about 12 liters of concrete mix and measure the time required to pass all concrete through it.

The passing ability is another characteristic of fresh SCC which is evaluated through the $\mathbf{L}$ box test. After filling the vertical part of the apparatuses by fresh concrete, the gate is removed to allow SCC to pass through the 3rebar obstructions and flow into the horizontal part. The ratio of the height of the mix in the two ends of the horizontal part $(\mathrm{H} 2 / \mathrm{H} 1)$ represents the filling ability, while the passing ability of mix can be evaluated by visual inspecting the area around the 3-rebar.

avraz_d@hotmail.com; and SCC(M30) respectively. Also, the time of T500 indicates flow which is measures the time taken in seconds from the time of the cone is removed to that horizontal flow reaches a diameter of $500 \mathrm{~mm}$.

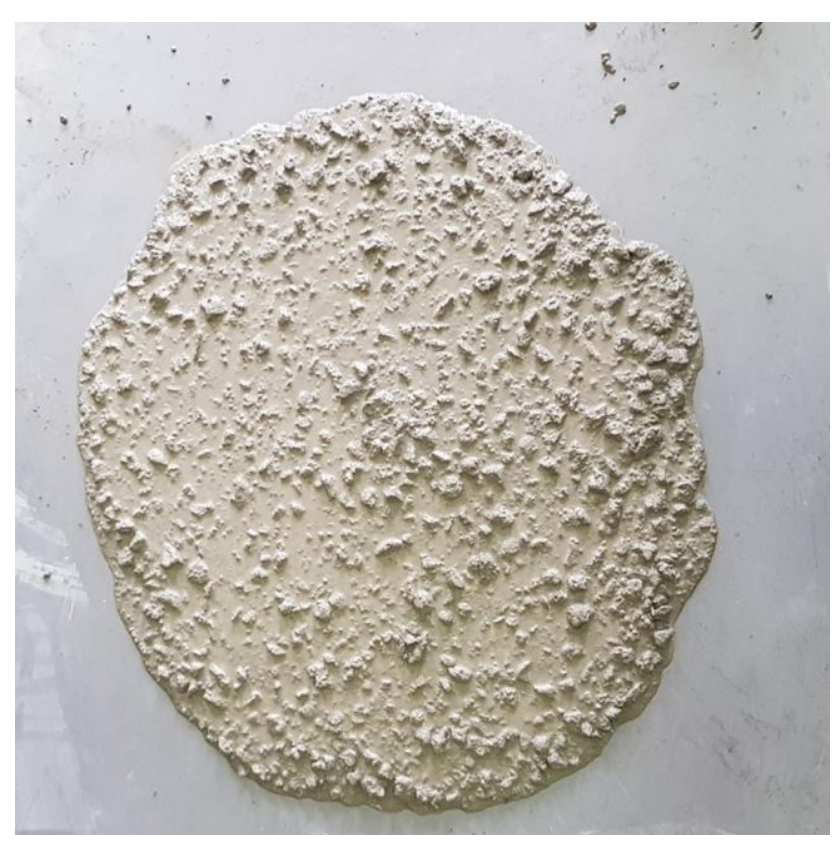

Fig. (5.2): Flow test of mix SCC(M30)

The J-ring test represents the passing ability of SCC, in which a slump cone is placed in the middle of the J-ring and filled with concrete, the cone is then lifted and the difference of height between (inside, outside, and center) of $\mathrm{j}$-ring is measured.

The ability of fresh SCC to protect its homogeneity of composition in the fresh state is defined as segregation resistance and is assessed by a sieve segregation resistance test, in which about 10 liters of fresh SCC is allowed to stand in the bowl for 15 minutes without any vibration. Then about $5 \mathrm{~kg}$ of the top part of that concrete is discharged into a sieve of the size of $5 \mathrm{~mm}$, and it allowed to stand on a sieve for 2 minutes, then the weight of the material that passed ghanim.qoja@uod.ac

${ }^{1}$ Corresponding author: College of Engineering, University of Duhok, Kurdistan Region, Iraq 
through the sieve is measured. The segregation resistance is noted as the ratio of the concrete passed over the sieve.

\section{RESULTS AND DISCUSSION}

The results obtained from the Laboratory tests on SCC are given below:

Table 6.1 shows the different test results carried out on the fresh SCC to achieve SCC properties. Several trials were carried out until mixes characterizing all the properties of SCC were obtained. The trails have been made on variation in $\mathrm{PF}$, further trials were made to evaluate the optimal dosage of superplasticizer for the final constituent of SCC. It was observed that a decrease in PF will increase the paste content, then blocking, bleeding and segregation occurs, while with a higher value of PF causes an increase in aggregate content and produces a mix with higher viscosity, then low filling ability and passing ability. According to the EFNARC guidelines, the final mixes fall within the range of acceptable values. The results of slump flow, T500, J-ring, L-box, V-funnel and sieve segregation resistance were presented in Table 6.1 below. Referring to Table 4.1, it was found that the mix contains a higher volume of limestone powder needs a higher dosage of superplasticizer, due to that the limestone powder increases the viscosity of the mix.

Table (6.1): Test results of workability of SCC

\begin{tabular}{|c|c|c|c|c|c|c|c|c|}
\hline Mix Type & P.F. & $\begin{array}{l}\text { Slump } \\
(\mathrm{mm})\end{array}$ & $\begin{array}{l}\text { T500 } \\
\text { (Sec) }\end{array}$ & $\begin{array}{l}\text { V-Funnel } \\
\text { (Sec) }\end{array}$ & L-Box $H_{0} / H_{1}$ & J-Ring & $\begin{array}{l}\text { Sieve Segregation } \\
\text { Resistance (\%) }\end{array}$ & $\begin{array}{l}\text { Visual } \\
\text { Check }\end{array}$ \\
\hline $\operatorname{SCC}(\mathrm{M} 60)$ & 1.08 & 630 & 8 & 40 & Block & NA & - & $\begin{array}{l}\text { Bleeding \& } \\
\text { Segregation }\end{array}$ \\
\hline $\operatorname{SCC}(\mathrm{M} 60)$ & 1.09 & NA & - & 30 & Block & NA & - & $\begin{array}{l}\text { Bleeding \& } \\
\text { Segregation }\end{array}$ \\
\hline $\operatorname{SCC}(\mathrm{M} 60)$ & 1.1 & 730 & 4 & 12.5 & 0.9 & 13 & - & Good \\
\hline $\operatorname{SCC}(M 60)$ & 1.11 & 690 & 4 & 8.5 & 0.95 & 8 & 13 & Excellent \\
\hline $\operatorname{SCC}(\mathrm{M} 30)$ & 1.17 & 630 & 10 & 18 & 0.6 & 16 & - & $\begin{array}{l}\text { High } \\
\text { Viscosity }\end{array}$ \\
\hline $\operatorname{SCC}(\mathrm{M} 30)$ & 1.14 & 600 & 9 & 12 & 0.85 & 12 & - & $\begin{array}{l}\text { High } \\
\text { Viscosity }\end{array}$ \\
\hline $\operatorname{SCC}(\mathrm{M} 30)$ & 1.13 & 660 & 5 & 8.5 & 0.85 & 9 & 4.5 & Excellent \\
\hline
\end{tabular}

\subsection{Hardened Properties (Compressive Strength)}

The test results of compressive strength for SCC(M30) and SCC(M60) mixes at the ages 7, 14,28 , and 56 days are tabulated in Table 6.2 and plotted in figure 6.1. All data presented are the mean of three experimental results. It was clear that the proposed mix design provides a promising result and achieves the required strengths within 28 days for both normal and high strength concrete.

Figure 6.1. provides the relationship between the compressive strength of SCC in MPa and age in days for the two mixes. The compressive strength continued to increase over the 56 - days curing period, however, SCC has the same mechanism of hydration to that of hydration in conventional vibrated concrete. Hydration development is influenced by the higher content of powder materials and admixtures. The incorporation of limestone powder in SCC leads to an increase in hydration reaction (Schutter, 2005). The effect of the limestone powder in SCC mixes was clear particularly at an early age (Table

6.2).

Table (6.2): Average compressive strength of SCC

\begin{tabular}{lll}
\hline Age (days) & $\begin{array}{l}\text { SCC(M30) } \\
(\mathrm{MPa})\end{array}$ & $\begin{array}{l}\text { SCC(M60) } \\
(\mathrm{MPa})\end{array}$ \\
\hline 7 & 21.8 & 45.7 \\
\hline 14 & 27.2 & 60.3 \\
\hline 28 & 31.4 & 66.3 \\
\hline 56 & 36.7 & 74.3 \\
\hline
\end{tabular}

avraz_d@hotmail.com; ghanim.qoja@uod.ac 


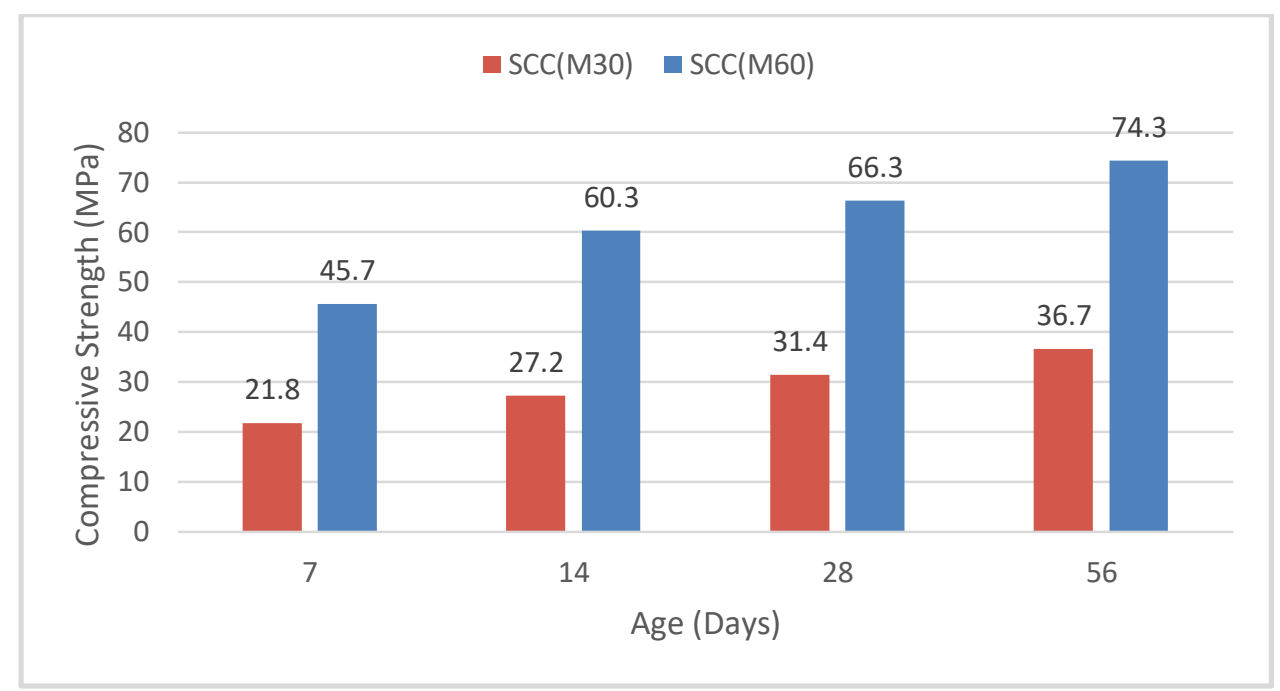

Fig. (6.1): Average compressive strength of SCC and age relationship

\section{CONCLUSIONS}

The following conclusions can be drawn based on the results from the present study:

1- The test results show that the proposed mix design method can produce successfully SCC of good quality for both normal and high strength concrete.

2- Trial mixes have to be made to maintain filling ability, passing ability, and stability.

3- The optimal PF of SCC with limestone filler is 1.13 for normal strength and 1.11 for high strength concrete.

4- Using limestone powder in SCC mixes can produce good concrete concerning both fresh and hardening properties.

5- Nan Su method can be applied when limestone powder is suggested.

6- The proposed method can be used for normal and high strength concrete

7- Recently, the development of SCC is one of the most important developments in the construction industry. Thus, we can make use of the final mix proportions for SCC production in the Duhok region.

\section{REFERENCES}

ACI 211.4R-08, A. (2008). Guide for selecting proportions for High Strength Concrete Using Portland Cement and Other Cementitious Materials. American Concrete Institute (ACI). ACI237R-07. (2007). Self-Consolidating Concrete. ACI Committee 237.
Caijun Shi,. Z. (2015). A review on mixture design methods for self-compacting concrete. Construction and Building Materials, 387398.

EFNARC. (2005). Guideline and Specification for Self Compacting Concrete.

Gritsada Sua-iam, N. M. (2013). Utilization of limestone powder to improve the properties of self-compacting concrete incorporating high volumes of untreated rice husk ash as fine aggregate. Construction and Building Materials, 455-464.

Hajime Okamura, m. O. (2003). Self-compacting Concrete. Advance Concrete Technology, 515.

Kareem, M. M. (2016). Self Compacting Concrete: Design, Properties, and Simulation of the Flow Characteristics in the L-Box . Ph.D. Thesis, Cardiff University, UK.

M. Benaicha, A. H. (2019). Dosage effect of superplasticizer on self-compacting concrete: correlation between rheology and strength. Journal of Materials Research and Technology, 2063-2069.

Nan Su, K.-C. H.-W. (2001). A simple Mix Design Method for Self-compacting Concrete. Cement and Concrete Research 31, 1799-1807.

Sadowski, L. (2018). Fundamental Fresh State Properties of Self-Consolidating Concrete: A Meta-Analysis of Mix Designs. Advances in Civil Engineering.

Schutter, P. A. (2005). Cement hydration in the presence of high filler content. cement and concrete research, 12.

Thrane L N, S. P. (2004). simulation of the Test Method "L-Box" for Self-Compacting Concrete. Annual Transactions of the Nordic Rheology Society. 12, 47-54.

avraz_d@hotmail.com; ghanim.qoja@uod.ac

${ }^{1}$ Corresponding author: College of Engineering, University of Duhok, Kurdistan Region, Iraq 